\title{
Pseudomonas knackmussii sp. nov.
}

Correspondence

Hans-Jürgen Busse

Hans-Juergen.Busse@

vu-wien.ac.at

\section{Andreas Stolz, ${ }^{1}$ Hans-Jürgen Busse ${ }^{2}$ and Peter Kämpfer ${ }^{3}$}

\author{
${ }^{1}$ Institut für Mikrobiologie, Universität Stuttgart, Allmandring 31, 70569 Stuttgart, Germany \\ ${ }^{2}$ Institut für Bakteriologie, Mykologie und Hygiene, Veterinärmedizinische Universität Wien, \\ Veterinärplatz 1, A-1210 Wien, Austria \\ ${ }^{3}$ Institut für Angewandte Mikrobiologie, Justus-Liebig-Universität Giessen, Heinrich-Buff-Ring \\ 26-32 (IFZ), D-35392 Giessen, Germany
}

The taxonomic position of Pseudomonas sp. B13 ${ }^{\top}$, isolated as a 3 -chlorobenzoate-degrading organism and used for several groundbreaking studies on the enzymology and genetics of the degradative pathway for haloaromatic compounds, was studied in detail. The previously performed physiological studies, the detection of ubiquinone $\mathrm{Q}-9$, the polyamine pattern with putrescine and spermidine as major polyamines, a fatty acid profile with $C_{18: 1} \omega 7 c$, summed feature 3 and $C_{16: 0}$ as quantitatively the most important constituents and the 16S rRNA gene sequence demonstrated that Pseudomonas sp. B13 ${ }^{\top}$ indeed belongs to the genus Pseudomonas. The sequence of the Pseudomonas sp. B13 ${ }^{\mathrm{T}} 16 \mathrm{~S}$ rRNA gene demonstrated a high degree of similarity with that of Pseudomonas citronellolis DSM 50332 ${ }^{\top}$ (98.9\%), Pseudomonas nitroreducens DSM $14399^{\top}$ (98.7\%), Pseudomonas jinjuensis DSM $16612^{\top}$ (98.1\%) and Pseudomonas multiresinivorans DSM $17553^{\top}$ (98.7\%). Thus it was shown that strain $P$ seudomonas sp. B13 ${ }^{\top}$ can be distinguished from related species by the ability/inability to assimilate $N$-acetylgalactosamine, D-galactose, putrescine, trans-aconitate and mesaconate and some differences in the fatty acid profile. The positioning of Pseudomonas sp. B13 ${ }^{\top}$ as a separate taxon was finally verified by DNA hybridization, which demonstrated less than $45 \%$ DNA-DNA similarity between strain Pseudomonas sp. B13 ${ }^{\top}$ and the reference strains. On the basis of these results, $P$ seudomonas sp. B13 $3^{\top}$ represents a novel species for which the name Pseudomonas knackmussii sp. nov. is proposed. The type strain is $\mathrm{B}_{13}{ }^{\top}$ (=DSM $6978^{\top}=$ LMG $23759^{\top}$ ).
Pseudomonas sp. $\mathrm{B} 13^{\mathrm{T}}$ was one of the first micro-organisms described that utilizes halogenated aromatic compounds as sole source of carbon and energy. The strain was isolated from a continuous enrichment in a chemostat with 3chlorobenzoate. The original inoculum of the chemostat was obtained from a sewage treatment plant in Göttingen, Germany (Dorn et al., 1974). The isolate was subsequently used to elaborate the degradative pathway of 3-chlorobenzoate and other halogenated aromatic compounds (e.g. Dorn \& Knackmuss, 1978a, b; Reineke \& Knackmuss, 1978a, b; Schmidt \& Knackmuss, 1980a, b; Kaschabek \& Reineke, 1992). Furthermore, Pseudomonas sp. B13 ${ }^{\mathrm{T}}$ was used for the first experiments that demonstrated the feasibility of in vivo and in vitro approaches for the construction of organisms with new metabolic capabilities (Reineke \& Knackmuss, 1979, 1980; Rubio et al., 1986; Ramos et al., 1986; Rojo et al., 1987). Very recently it was demonstrated that the ability to degrade 3- and 4-chlorocatechol is encoded on a selftransferable DNA element in Pseudomonas sp. $\mathrm{B}_{13}^{\mathrm{T}}$ (Gaillard et al., 2006). Affilation of Pseudomonas sp. B13 ${ }^{\mathrm{T}}$

The GenBank/EMBL/DDBJ accession number for the 16S rRNA gene sequence of Pseudomonas sp. B13 ${ }^{\top}$ is AF039489. to the genus Pseudomonas sensu stricto has already been demonstrated by Busse et al. (1989) based on analysis of the quinone system and polyamine pattern.

Cells of Pseudomonas sp. $\mathrm{B} 13^{\mathrm{T}}$ are Gram-negative, polarly flagellated, motile short rods. The oxidase and catalase reactions were positive. Based on these results and several physiological tests which were performed in accordance with the study of Stanier et al. (1966) on the aerobic pseudomonads (see strain description), it was suggested that the strain belongs to the pseudomonads and was most closely related to Pseudomonas fluorescens, although no fluorescent pigments were observed during growth (Dorn et al., 1974).

The 16S rRNA gene sequence of Pseudomonas sp. $\mathrm{B} 13^{\mathrm{T}}$ containing a continuous stretch of 1528 bp has been deposited at the NCBI database under the accession number AF039489 (Wischnak et al., 1998). Sequence searches at the NCBI database demonstrated that Pseudomonas sp. B13 ${ }^{\mathrm{T}}$ indeed belongs to the genus Pseudomonas as it is currently defined and the closest relatives of Pseudomonas sp. B13 ${ }^{\mathrm{T}}$ were found to be Pseudomonas citronellolis DSM $50332^{\mathrm{T}}$, Pseudomonas nitroreducens DSM $14399^{\mathrm{T}}$, Pseudomonas 
jinjuensis DSM $16612^{\mathrm{T}}$ and Pseudomonas multiresinivorans DSM $17553^{\mathrm{T}}$ with $98.1-98.9 \%$ sequence similarity. No other type strain of the genus showed sequence similarity values $>97 \%$ to the $16 \mathrm{~S}$ rRNA gene sequence from Pseudomonas sp. $\mathrm{B}_{13}{ }^{\mathrm{T}}$. This clearly demonstrated that Pseudomonas sp. $\mathrm{B} 13^{\mathrm{T}}$ belongs in the respective subcluster of pseudomonads which is part of the Pseudomonas aeruginosa subgroup as defined by $16 \mathrm{~S}$ rRNA gene sequence comparisons (Anzai et al., 2000). Since results from DNA-DNA hybridizations have demonstrated that $P$. multiresinivorans is a junior homonym of $P$. nitroreducens (E. Lang, unpublished), P. multiresinivorans DSM $17553^{\mathrm{T}}$ was not included in all comparative analyses.

Analysis of the carbon substrate utilization for growth of Pseudomonas sp. $\mathrm{B}^{\mathrm{T}}{ }^{\mathrm{T}}, P$. citronellolis DSM $50332^{\mathrm{T}}, P$. nitroreducens DSM $14399^{\mathrm{T}}$, P. jinjuensis DSM $16612^{\mathrm{T}}$ and $P$. multiresinivorans DSM $17553^{\mathrm{T}}$ demonstrated that all five strains converted a wide range of organic compounds and clearly resembled each other in their metabolic traits. Nevertheless, the five strains could be distinguished by their ability/inability to assimilate $\mathrm{N}$-acetylgalactosamine, Dgalactose, putrescine, trans-aconitate and mesaconate (Table 1).

The G $+\mathrm{C}$ content of the genomic DNA of Pseudomonas sp. $\mathrm{B} 13^{\mathrm{T}}$ was determined to be $67.3 \pm 0.5 \mathrm{~mol} \%$. The quinone system of Pseudomonas sp. B13 ${ }^{\mathrm{T}}$ was previously shown to consist of the major compound ubiquinone Q-9 and the polyamine pattern to show the major compounds putrescine and spermidine and minor amounts of 1,3-diaminopropane, cadaverine and spermine (Busse et al., 1989). Re-examination of the quinone system by HPLC as described previously (Ventosa et al., 1993; Altenburger et al., 1996) but using an HPLC system consisting of a JASCO PU 2080 Plus Pump and JASCO UV-2075 Plus UV/ VIS detector, and the polyamine pattern as described by Busse \& Auling (1988) and Busse et al. (1997) but employing a JASCO PU 2080 Plus pump, confirmed previous results. The quinone system of Pseudomonas sp. $\mathrm{B} 13^{\mathrm{T}}$ consisted of the major compound Q-9 (94\%) and minor amounts of Q8. A similar quinone system was detected for $P$. citronellolis DSM 50332 $2^{\mathrm{T}}$, P. nitroreducens DSM $14399^{\mathrm{T}}$ and P. jinjuensis DSM $16612^{\mathrm{T}}$, exhibiting 98, 97 and $98 \%$ Q-9, respectively, and minor amounts of Q-8. The polyamine pattern of Pseudomonas sp. $\mathrm{B} 3^{\mathrm{T}}$ consisted of major amounts of putrescine $\left[94.2 \mu \mathrm{mol}(\mathrm{g} \text { dry weight })^{-1}\right]$, spermidine $\left[13.5 \mu \mathrm{mol}(\mathrm{g} \text { dry weight })^{-1}\right]$ and cadaverine $[8.8 \mu \mathrm{mol}(\mathrm{g}$ dry weight $\left.)^{-1}\right]$. Furthermore, small amounts of 1,3diaminopropane $\left.[1.2 \mu \mathrm{mol} \text { (g dry weight })^{-1}\right]$ and spermine $\left.[0.3 \mu \mathrm{mol} \text { (g dry weight })^{-1}\right]$ were also detected. The reference strains exhibited similar polyamine patterns showing only some remarkable differences in the content of cadaverine. The patterns were as follows [amounts in $\mu \mathrm{mol}$ (g dry weight $)^{-1}$ ]: P. citronellolis DSM $50332^{\mathrm{T}}$ : putrescine 95.7, spermidine 12.8 , cadaverine $0.8,1,3-$ diaminopropane 1.0 , spermine $0.9 ;$ P. nitroreducens DSM $14399^{\mathrm{T}}$ : putrescine 84.8 , spermidine 14.4 , cadaverine 10.1 , 1,3-diaminopropane 7.9, spermine 1.3 ; and P. jinjuensis
Table 1. Physiological characteristics of the type strains of Pseudomonas species related to Pseudomonas sp. B13

Taxa: 1, Pseudomonas sp. B13 ${ }^{\mathrm{T}}$; 2, P. citronellolis DSM $50332^{\mathrm{T}} ; 3$, P. nitroreducens DSM $14399^{\mathrm{T}} ; 4$, P. multiresinivorans DSM $17553^{\mathrm{T}}$; 5, P. jinjuensis DSM $16612^{\mathrm{T}}$. +, Positive; -, negative; $(+)$, weakly positive. All strains were positive for: acid formation from D-glucose $\mathrm{e}^{b d}$; utilization of D-gluconate ${ }^{c d}, \mathrm{D}$-glucose $\mathrm{e}^{a c d}, \mathrm{D}$-fructose, cis-aconitate, adipate, 4-aminobutyrate, azelate, citrate ${ }^{a c d}$, fumarate $^{a}$, glutarate, DL-3-hydroxybutyrate, itaconate, DL-lactate ${ }^{a c}$, L-mala$\mathrm{te}^{a}$, pyruvate ${ }^{a b}, 2$-oxoglutarate, suberate, L-alanine ${ }^{a c}, \beta$-alanine, L-aspartate ${ }^{c}$, L-histidine ${ }^{a}$, L-leucine ${ }^{c}$, L-ornithine, L-proline $e^{a c}, \quad 4-$ hydroxybenzoate $^{a}$ and phenylacetate ${ }^{c}$; hydrolysis of bis- $p$ NP phosphate, $p \mathrm{NP}$ phosphorylcholine, L-alanine $p \mathrm{NA}, \mathrm{L}$-glutamate-3-carboxy- $p \mathrm{NA}$ and L-proline $p \mathrm{NA}$. All strains were negative for: acid formation from sucrose, D-mannitol, dulcitol, salicin, adonitol, inositol, D-sorbitol, L-arabinose, raffinose, L-rhamnose, maltose, Dxylose, trehalose, cellobiose, methyl $\alpha$-D-glucoside, erythritol, melibiose, D-arabitol and D-mannose ${ }^{a}$; utilization of $N$-acetyl-D-glucosamine $^{c}, \quad$ L-arabinose ${ }^{a c}, p$-arbutin, D-cellobiose ${ }^{a}$, D-trehalose, Dxylose $^{a b}$, adonitol, inositol ${ }^{a}$, maltitol, D-mannitol ${ }^{a c}$, sorbitol, acetate, propionate and L-tryptophan; hydrolysis of $p \mathrm{NP} \beta$-D-galactopyranoside $c$, $p$ NP $\beta$-D-glucuronide, $p$ NP $\alpha$-D-glucopyranoside, $p \mathrm{NP}$ $\beta$-D-glucopyranoside and $p \mathrm{NP} \beta$-D-xylopyranoside. $p \mathrm{NP}$, paranitrophenyl; $p \mathrm{NA}$, para-nitroanilide.

\begin{tabular}{|llllll|}
\hline Test & $\mathbf{1}$ & $\mathbf{2}$ & $\mathbf{3}$ & $\mathbf{4}$ & $\mathbf{5}$ \\
\hline Assimilation of: & & & & & \\
$\quad$ N-Acetylgalactosamine & - & - & + & - & - \\
D-Galactose & $-{ }^{a}$ & + & - & $-^{b}$ & - \\
Putrescine & + & + & + & + & - \\
trans-Aconitate & - & + & + & + & + \\
Mesaconate & - & + & + & + & - \\
\hline
\end{tabular}

$a-d$, Tested using a different method in another study; results were congruent with those of this study. a, Dorn et al. (1974) with Pseudomonas sp. B13 ${ }^{\mathrm{T}}$; $b$, Mohn et al. (1999) with P. multiresinivorans; $c$, Kwon et al. (2003) with $P$. jinjuensis; $d$, Palleroni (2005) with P. nitroreducens and P. citronellolis.

DSM $16612^{\mathrm{T}}$ : putrescine 100.5 , spermidine 18.5 ; cadaverine 1.2, 1,3-diaminopropane 0.6 , spermine 3.2. The quinone system and polyamine patterns are in excellent agreement with those reported for other species of the genus Pseudomonas sensu stricto (Busse \& Auling, 1988; Auling et al., 1991).

Polar lipids were analysed as described by Tindall (1990). Pseudomonas sp. B13 ${ }^{\mathrm{T}}$ (Fig. 1) and the reference strains $P$. citronellolis DSM $50332^{\mathrm{T}}, P$. nitroreducens DSM $14399^{\mathrm{T}}$ and P. jinjuensis DSM $16612^{\mathrm{T}}$ (results not shown) exhibited almost identical profiles. Differences in the presence of trace amounts of some unknown lipids may occur but could not be unambiguously identified. The polar lipid profile of Pseudomonas sp. $\mathrm{B} 3^{\mathrm{T}}$ consisted of the major compounds phosphatidylethanolamine, diphosphatidylglycerol and phosphatidylglycerol, moderate amounts of four 


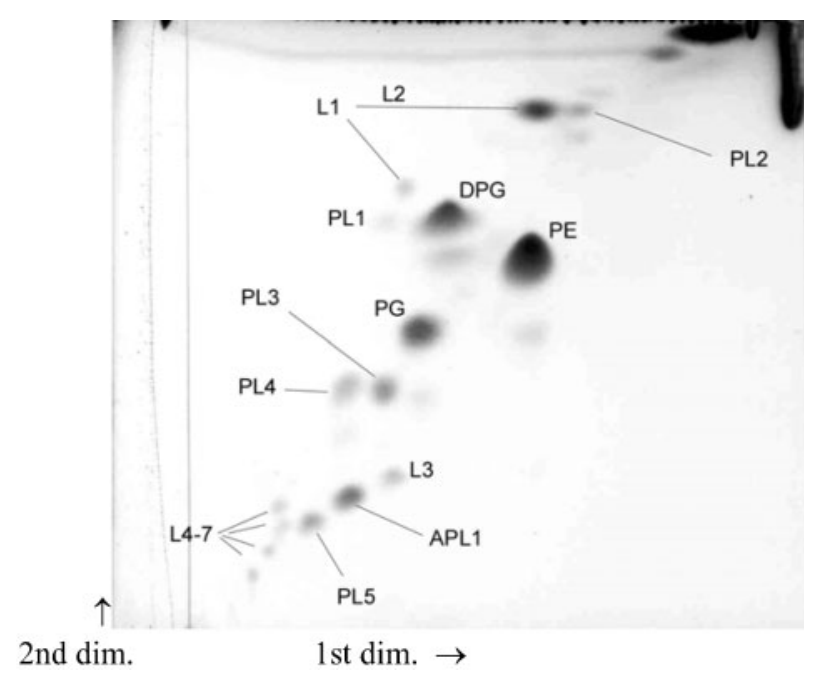

Fig. 1. Two-dimensional TLC of polar lipids of Pseudomonas sp. $B 13^{\top}$. APL1, unknown aminophospholipid; DPG, diphosphatidylglycerol; L1-7, unknown polar lipids; PE, phosphatidylethanolamine; PG, phosphatidylglycerol; PL1-5, unknown phospholipids.

unknown phospholipids (PL2-5), an unknown aminolipid (APL1) and two unknown polar lipids (L2, 3) and minor to trace amounts of one phospholipid (PL1) and five unknown polar lipids (L1, 4-7). Two highly hydrophobic lipids were also detected (Fig. 1). These polar lipid profiles contain the same major compounds reported for two other species of the genus, Pseudomonas psychrotolerans DSM $15758^{\mathrm{T}}$ and Pseudomonas oleovorans DSM $1045^{\mathrm{T}}$, and the misnamed strain Pseudomonas oleovorans ATCC 29347, but they lack phosphatidylcholine, detected in major to moderate amounts in P. psychrotolerans DSM $15758^{\mathrm{T}}$ and P. oleovorans DSM $1045^{\mathrm{T}}$ (Hauser et al., 2004). Also differences in the presence/absence of minor compounds characteristic for representatives of one or the other group were found. These observations indicate that polar lipid profiles may be useful for characterizing subgroups within the genus Pseudomonas sensu stricto and hence their analysis for classification of novel species can be strongly recommended.

The fatty acid profiles of strain Pseudomonas sp. $\mathrm{B} 13^{\mathrm{T}}, P$. citronellolis DSM $50332^{\mathrm{T}}$, P. nitroreducens DSM $14399^{\mathrm{T}}$ and $P$. jinjuensis DSM $16612^{\mathrm{T}}$ were determined as described previously by Kämpfer et al. (1997). All four strains had rather similar fatty acid profiles, with $\mathrm{C}_{18: 1} \omega 7 c(29.8-41.8 \%)$, summed feature $3(16.5-24.8 \%)$ and $\mathrm{C}_{16: 0}(19.4-21.2 \%)$ as quantitatively the most important constituents (Table 2).

DNA-DNA hybridizations were performed between Pseudomonas sp. $\mathrm{B} 13^{\mathrm{T}}$ and the four reference strains as described by Kämpfer et al. (2003). The similarity values (mean values of two individual analyses) determined between the genomic DNA of Pseudomonas sp. $\mathrm{B} 13^{\mathrm{T}}$ and that of the reference strains were as follows: P. citronellolis DSM 50332 ${ }^{\mathrm{T}}, 44.5 \%$; P. nitroreducens DSM $14399^{\mathrm{T}}, 35.2 \%$;
Table 2. Major fatty acid composition (\%) of type strains of species of the genus Pseudomonas

Strains: 1, Pseudomonas sp. B13 ${ }^{\mathrm{T}} ; 2$, P. citronellolis DSM $50332^{\mathrm{T}}$; 3, P. nitroreducens DSM $14399^{\mathrm{T}}$; 4, P. jinjuensis DSM $16612^{\mathrm{T}}$. All strains were grown on trypticase soy broth agar at $28^{\circ} \mathrm{C}$ for $48 \mathrm{~h}$ prior to fatty acid analysis.

\begin{tabular}{|lrrrr|}
\hline Fatty acid & $\mathbf{1}$ & $\mathbf{2}$ & $\mathbf{3}$ & $\mathbf{4}$ \\
\hline Saturated fatty acids & & & & \\
$\mathrm{C}_{10: 0}$ & & 0.7 & & 0.3 \\
$\mathrm{C}_{12: 0}$ & 3.7 & 3.3 & 1.5 & 6.3 \\
$\mathrm{C}_{14: 0}$ & 0.8 & 0.8 & 0.4 & 0.5 \\
$\mathrm{C}_{15: 0}$ & 0.3 & 0.3 & & 1.0 \\
$\mathrm{C}_{16: 0}$ & 19.4 & 21.0 & 21.2 & 19.6 \\
$\mathrm{C}_{17: 0}$ & & & & 0.8 \\
$\mathrm{C}_{18: 0}$ & 0.3 & 0.3 & 0.7 & 0.4 \\
Unsaturated fatty acids $^{*}$ & & & & \\
$\mathrm{C}_{17: 1} \omega 8 c$ & & & & 1.2 \\
$\mathrm{C}_{18: 1} \omega 7 c$ & 36.6 & 35.7 & 41.8 & 29.8 \\
Hydroxy fatty acids & & & & \\
$\mathrm{C}_{8: 0}$ 3-OH & & 0.4 & & \\
$\mathrm{C}_{10: 0}$ 3-OH & 3.5 & 6.2 & 3.8 & 3.7 \\
$\mathrm{C}_{12: 0}$ 2-OH & 3.5 & 3.6 & 5.0 & 1.5 \\
$\mathrm{C}_{12: 0}$ 3-OH & 4.0 & 3.5 & 3.9 & 3.2 \\
Summed feature 3† & 24.8 & 17.8 & 16.5 & 24.5 \\
Cyclopropane acids & & & & \\
$\mathrm{C}_{17: 0}$ cyclo & 2.7 & 2.7 & 1.6 & 4.7 \\
$\mathrm{C}_{19: 0}$ cyclo $\omega 8 c$ & 0.4 & 3.2 & 0.9 & 2.6 \\
\hline
\end{tabular}

${ }^{\star}$ For unsaturated fatty acids, the position of the double bond is located by counting from the methyl $(\omega)$ end of the carbon chain. cis isomers are indicated by the suffix $c$.

$\uparrow$ Summed features are groups of two or three fatty acids that cannot be separated by GLC with the MIDI system. Summed feature 3 contains one or more of the fatty acids $\mathrm{C}_{16: 1} \omega 7 c$ and $\mathrm{C}_{15: 0}$ iso $2-\mathrm{OH}$.

P. jinjuensis DSM $16612^{\mathrm{T}}, 38.7 \%$; and P. multiresinivorans DSM $17553^{\mathrm{T}}, 38.0 \%$.

Organisms sharing a 16S rRNA gene sequence similarity lower than $97 \%$ are usually regarded as belonging to different bacterial species (Stackebrandt \& Goebel, 1994). In the genus Pseudomonas, several recently reported Pseudomonas species have shown 16S rRNA gene sequence similarities of more than $99 \%$ to other established species (Achouak et al., 2000; Andersen et al., 2000; Hauser et al., 2004; Kwon et al., 2003; Sikorski et al., 2001). This situation also seems to be relevant for the subgroup of pseudomonads analysed in the present study. Thus from the DNA-DNA hybridization studies and the physiological tests it is evident that Pseudomonas sp. $\mathrm{B} 13^{\mathrm{T}}$ represents a distinct, previously undescribed species within the genus Pseudomonas. In conclusion, Pseudomonas sp. $\mathrm{B} 13^{\mathrm{T}}$ is phylogenetically and physiologically unique and represents a novel species within 
the genus Pseudomonas, for which we propose the name Pseudomonas knackmussii sp. nov.

\section{Description of Pseudomonas knackmussii sp. nov.}

Pseudomonas knackmussii (knack.muss'i.i. N.L. masc. gen. n. knackmussii of Knackmuss, in honour of Hans-Joachim Knackmuss, who initiated the biochemical studies about the degradation of chlorinated aromatics and other xenobiotic compounds by strain $\mathrm{B}^{\mathrm{T}}{ }^{\mathrm{T}}$ and various other microorganisms).

Cells are Gram-negative, polarly flagellated, motile short rods. Oxidase- and catalase-positive. On solid 3-chlorobenzoate-mineral agar the strain forms round, smooth, colourless, opaque colonies of 1-2 mm diameter when grown at $28{ }^{\circ} \mathrm{C}$ for 3 days. Growth is observed at $20-41{ }^{\circ} \mathrm{C}$ but not at $4{ }^{\circ} \mathrm{C}$. Good growth is found at $\mathrm{pH} 6.0$ and 8.3; there is no growth at $\mathrm{pH} 5$ or $\mathrm{pH} 9$. No fluorescent or phenazine pigments are formed. Nitrate is not reduced under aerobic or anaerobic conditions. No liquefaction of gelatin, degradation of starch or cellulose, or formation of ethanol from acetate is detected. The strain is positive for: acid formation from D-glucose; utilization of D-gluconate, D-glucose, D-fructose, cis-aconitate, adipate, 4-aminobutyrate, azelate, citrate, fumarate, glutarate, DL-3hydroxybutyrate, itaconate, DL-lactate, L-malate, pyruvate, 2 -oxoglutarate, suberate, L-alanine, $\beta$-alanine, L-aspartate, L-histidine, L-leucine, L-ornithine, L-proline, 4-hydroxybenzoate, phenylacetate and putrescine; hydrolysis of bis$p \mathrm{NP}$ phosphate, $p \mathrm{NP}$ phosphorylcholine, L-alanine $p \mathrm{NA}$, L-glutamate-3-carboxy $p \mathrm{NA}$ and L-proline $p \mathrm{NA}(p \mathrm{NP}$, paranitrophenyl; $p \mathrm{NA}$, para-nitroanilide). Acids are not produced from sucrose, D-mannitol, dulcitol, salicin, adonitol, inositol, D-sorbitol, L-arabinose, raffinose, L-rhamnose, maltose, D-xylose, trehalose, cellobiose, methyl $\alpha$-D-glucoside, erythritol, melibiose, D-arabitol, D-mannose, $N$-acetylgalactosamine, D-galactose, trans-aconitate or mesaconate. The following glycosides are not hydrolysed: $p \mathrm{NP}$ $\beta$-D-galactopyranoside, $p \mathrm{NP} \beta$-D-glucuronide, $p \mathrm{NP} \alpha$-Dglucopyranoside, $p \mathrm{NP} \quad \beta$-D-glucopyranoside and $p \mathrm{NP}$ $\beta$-D-xylopyranoside. $N$-Acetyl-D-glucosamine, L-arabinose, p-arbutin, D-cellobiose, D-trehalose, D-xylose, adonitol, inositol, maltitol, D-mannitol, sorbitol, acetate, propionate and L-tryptophan are not utilized. The quinone system consists predominantly of ubiquinone Q-9. Putrescine and spermidine are the major polyamines. The polar lipid profile consists of the major compounds phosphatidylethanolamine, diphosphatidylglycerol and phosphatidylglycerol, moderate amounts of four unknown phospholipids, an unknown aminolipid and two unknown polar lipids, and minor to trace amounts of one phospholipid and five unknown polar lipids. Two highly hydrophobic lipids are also detectable. Fatty acid composition is as follows: $\mathrm{C}_{18: 1} \omega 7 c(36.6 \%)$, summed feature $3(24.8 \%)$ and $\mathrm{C}_{16: 0}$ $(19.4 \%), \mathrm{C}_{12: 0} 3-\mathrm{OH}(4.0 \%), \mathrm{C}_{12: 0}(3.7 \%), \mathrm{C}_{12: 0} 2-\mathrm{OH}$ (3.5\%), $\mathrm{C}_{10: 0} 3-\mathrm{OH}(3.5 \%)$ and $\mathrm{C}_{17: 0}$ cyclo $(2.7 \%)$.
The type strain is $B 13^{\mathrm{T}}\left(=\mathrm{DSM} 6978^{\mathrm{T}}=\mathrm{LMG} 23759^{\mathrm{T}}\right)$, isolated from a sewage treatment plant in Göttingen (Germany) after continuous enrichment with 3-chlorobenzoate.

\section{Acknowledgements}

We want to thank J. P. Euzéby for checking the species epithet for correctness.

\section{References}

Achouak, W., Sudra, L., Heulin, T., Meyer, J.-M., Fromin, N., Degraeve, S., Christen, R. \& Gardan, L. (2000). Pseudomonas brassicacearum sp. nov. and Pseudomonas thivervalensis sp. nov., two root-associated bacteria isolated from Brassica napus and Arabidopsis thaliana. Int J Syst Evol Microbiol 50, 9-18.

Altenburger, P., Kämpfer, P., Makristathis, A., Lubitz, W. \& Busse, H. J. (1996). Classification of bacteria isolated from a medieval wall painting. J Biotechnol 47, 39-52.

Andersen, S. M., Johnsen, K., Sørensen, J., Nielsen, P. \& Jacobsen, C. S. (2000). Pseudomonas frederiksbergensis sp. nov., isolated from soil at a coal gasification site. Int J Syst Evol Microbiol 50, 1957-1964.

Anzai, Y., Kim, H., Park, J.-Y., Wakabayashi, H. \& Oyaizu, H. (2000). Phylogenetic affiliation of the pseudomonads based on 16S rRNA sequence. Int J Syst Evol Microbiol 50, 1563-1589.

Auling, G., Busse, H.-J., Pilz, F., Webb, L., Kneifel, H. \& Claus, D. (1991). Rapid differentiation by polyamine analysis of Xanthomonas strains from phytopathogenic pseudomonads and other members of the class Proteobacteria interacting with plants. Int J Syst Bacteriol 41, 223-228.

Busse, H.-J. \& Auling, G. (1988). Polyamine pattern as a chemotaxonomic marker within the Proteobacteria. Syst Appl Microbiol 11, $1-8$.

Busse, H.-J., El Banna, T. \& Auling, G. (1989). Evaluation of different approaches for identification of xenobiotic-degrading pseudomonads. Appl Environ Microbiol 55, 1578-1583.

Busse, H.-J., Bunka, S., Hensel, A. \& Lubitz, W. (1997). Discrimination of members of the family Pasteurellaceae based on polyamine patterns. Int J Syst Bacteriol 47, 698-708.

Dorn, E. \& Knackmuss, H.-J. (1978a). Chemical structure and biodegradability of halogenated aromatic compounds. Two catechol 1,2-dioxygenases from a 3-chlorobenzoate-grown pseudomonad. Biochem J 174, 73-84.

Dorn, E. \& Knackmuss, H.-J. (1978b). Chemical structure and biodegradability of halogenated aromatic compounds. Substituent effect on 1,2-dioxygenation of catechol. Biochem J 174, 85-94.

Dorn, E., Hellwig, M., Reineke, W. \& Knackmuss, H.-J. (1974). Isolation and characterization of a 3-chlorobenzoate degrading pseudomonad. Arch Microbiol 99, 61-70.

Gaillard, M., Vallaeys, T., Vorholter, F. J., Minoia, M., Werlen, C., Sentchilo, V., Pühler, A. \& van der Meer, J. R. (2006). The $c l c$ element of Pseudomonas sp. strain B13, a genomic island with various catabolic properties. J Bacteriol 188, 1999-2013.

Hauser, E., Kämpfer, P. \& Busse, H.-J. (2004). Pseudomonas psychrotolerans sp. nov. Int J Syst Evol Microbiol 54, 1633-1637.

Kämpfer, P., Denner, E. B. M., Meyer, S., Moore, E. R. B. \& Busse, H.-J. (1997). Classification of "Pseudomonas azotocolligans" Anderson 1955, 132, in the genus Sphingomonas as Sphingomonas trueperi sp. nov. Int J Syst Bacteriol 47, 577-583. 
Kämpfer, P., Buczolits, S., Albrecht, A., Busse, H.-J. \& Stackebrandt, E. (2003). Towards a standardized format for the description of a novel species (of an established genus): Ochrobactrum gallinifaecis sp. nov. Int J Syst Bacteriol 53, 893-896.

Kaschabek, S. R. \& Reineke, W. (1992). Maleylacetate reductase of Pseudomonas sp. strain B13: dechlorination of chloromaleylacetates, metabolites in the degradation of chloroaromatic compounds. Arch Microbiol 158, 412-417.

Kwon, S. W., Kim, J. S., Park, I. C., Yoon, S. H., Park, D. H., Lim, C. K. \& Go, S. J. (2003). Pseudomonas koreensis sp. nov., Pseudomonas umsongensis sp. nov. and Pseudomonas jinjuensis sp. nov., novel species from farm soils in Korea. Int J Syst Evol Microbiol 53, 21-27.

Mohn, W. W., Wilson, A. E., Bicho, P. \& Moore, E. R. B. (1999). Physiological and phylogenetic diversity of bacteria growing on resin acids. Syst Appl Microbiol 22, 68-78.

Palleroni, N. J. (2005). Genus I Pseudomonas Migula 1894, 237AL. In Bergey's Manual of Systematic Bacteriology, The Proteobacteria Part B The Gammaproteobacteria, 2nd edn, vol. 2, pp. 323-379. Edited by D. J. Brenner, N. R. Krieg \& J. T. Staley. Heidelberg \& New York: Springer.

Ramos, J. L., Stolz, A., Reineke, W. \& Timmis, K. N. (1986). Altered effector specificities in regulators of gene expression: TOL plasmid $x y l S$ mutants and their use to engineer expansion of the range of aromatics degraded by bacteria. Proc Natl Acad Sci U S A 83, 8467-8471.

Reineke, W. \& Knackmuss, H.-J. (1978a). Chemical structure and biodegradability of halogenated aromatic compounds. Substituent effects on 1,2-dioxygenation of benzoic acid. Biochim Biophys Acta 542, 412-423.

Reineke, W. \& Knackmuss, H.-J. (1978b). Chemical structure and biodegradability of halogenated aromatic compounds. Substituent effects on dehydrogenation of 3,5-cyclohexadiene-1,2-diol-1-carboxylic acid. Biochim Biophys Acta 542, 424-429.

Reineke, W. \& Knackmuss, H.-J. (1979). Construction of haloaromatics utilising bacteria. Nature 277, 385-386.
Reineke, W. \& Knackmuss, H.-J. (1980). Hybrid pathway for chlorobenzoate metabolism in Pseudomonas sp. B13 derivatives. J Bacteriol 142, 467-473.

Rojo, F., Pieper, D. H., Engesser, K.-H., Knackmuss, H.-J. \& Timmis, K. N. (1987). Assemblage of ortho-cleavage route for simultaneous degradation of chloro- and methylaromatics. Science 238, 1395-1398.

Rubio, M. A., Engesser, K.-H. \& Knackmuss, H.-J. (1986). Microbial metabolism of chlorosalicylates: accelerated evolution of natural genetic exchange. Arch Microbiol 145, 116-122.

Schmidt, E. \& Knackmuss, H.-J. (1980a). Chemical structure and biodegradability of halogenated aromatic compounds. Halogenated muconic acids as intermediates. Biochem J 192, 331-337.

Schmidt, E. \& Knackmuss, H.-J. (1980b). Chemical structure and biodegradability of halogenated aromatic compounds. Conversion of chlorinated muconic acids into maleoylacetic acid. Biochem J 192, 339-347.

Sikorski, J., Stackebrandt, E. \& Wackernagel, W. (2001). Pseudomonas kilonensis sp. nov., a bacterium isolated from agricultural soil. Int J Syst Evol Microbiol 51, 1549-1555.

Stackebrandt, E. \& Goebel, B. M. (1994). Taxonomic note: a place for DNA-DNA reassociation and 16S rRNA sequence analysis in the present species definition in bacteriology. Int J Syst Bacteriol 44, 846-849.

Stanier, R. Y., Palleroni, N. J. \& Doudoroff, M. (1966). The aerobic pseudomonads: a taxonomic study. J Gen Microbiol 43, 159-271.

Tindall, B. J. (1990). A comparative study of the lipid composition of Halobacterium saccharovorum from various sources. Syst Appl Microbiol 13, 128-130.

Ventosa, A., Marquez, M. C., Kocur, M. \& Tindall, B. J. (1993). Comparative study of "Micrococcus sp." strains CCM 168 and CCM 1405 and members of the genus Salinicoccus. Int J Syst Bacteriol 43, 245-248.

Wischnak, C., Löffler, F. E., Li, J., Urbance, J. W. \& Müller, R. (1998). Pseudomonas sp. strain 273, an aerobic $\alpha, \omega$-dichloroalkane degrading bacterium. Appl Environ Microbiol 64, 3507-3511. 